\title{
Results from a Geographically Focused, Community-Based HCV Screening, Linkage-to-Care and Patient Navigation Program
}

\author{
Stacey B. Trooskin, MD PhD ${ }^{7}$, Joanna Poceta, $B A^{2,4}$, Caitlin M. Towey, $M P H^{3,4}$, \\ Annajane Yolken, BS ${ }^{3,4}$, Jennifer S. Rose, PhD ${ }^{5}$, Najia L. Luaman, MPH ${ }^{4}$, Ta-Wanda L. Preston, BA 4 , \\ Philip A. Chan, MD MS ${ }^{2,6}$, Curt Beckwith, MD'2,6, Sophie C. Feller, BA7 , Hwajin Lee, BS ${ }^{3,4}$, and Amy S. \\ Nunn, MS SCD 3,4
}

\begin{abstract}
'Division of Infectious Diseases, Drexel University College of Medicine, Philadelphia, PA, USA; ${ }^{2}$ Division of Infectious Diseases, Miriam Hospital, Providence, RI, USA; ${ }^{3}$ Department of Behavioral and Social Sciences, Brown University School of Public Health, Providence, RI, USA; ${ }^{4}$ Rhode Island Public Health Institute, Providence, RI, USA; ${ }^{5}$ Department of Psychology, Wesleyan University, Middletown, CT, USA; 'Brown University Warren Alpert Medical School, Providence, RI, USA; ${ }^{7}$ Division of Infectious Diseases, Jefferson Medical College, Philadelphia, PA, USA.
\end{abstract}

BACKGROUND: Many of the five million Americans chronically infected with hepatitis $\mathrm{C}(\mathrm{HCV})$ are unaware of their infection and are not in care.

OBJECTIVE: We implemented and evaluated $\mathrm{HCV}$ screening and linkage-to-care interventions in a community setting.

DESIGN: We developed a comprehensive, communitybased HCV screening and linkage-to-care program in a medically underserved neighborhood with high rates of $\mathrm{HCV}$ infection in Philadelphia, Pennsylvania. We provided patient navigation services to enroll uninsured patients in insurance programs, facilitate referrals from primary care physicians and link patients to an HCV infectious disease specialist with intention to treat and cure.

PATIENTS: Philadelphia residents were recruited through street outreach.

MAIN MEASURES: We measured anti-HCV seroprevalence and diagnosis, linkage and retention in care outcomes for chronically infected patients.

KEY RESULTS: We screened 1,301 participants for $\mathrm{HCV}$; anti-HCV seroprevalence was $3.9 \%$ and $2.8 \%$ of all patients were chronically infected. Half of chronically infected patients were newly diagnosed; the remaining patients were aware of infection but not in care. We provided confirmatory RNA testing and results, assisted patients with attaining insurance and linked most chronically infected patients to a primary care provider. The biggest barrier to retaining patients in care was obtaining referrals for subspecialty providers; however, we obtained referrals for $64 \%$ of chronically infected participants and have retained most in subspecialty $\mathrm{HCV}$ care. Several have commenced treatment.

CONCLUSIONS: Non-clinical screening programs with patient navigator services are an effective means to diagnose, link, retain and re-engage patients in HCV care. Eliminating referral requirements for subspecialty care might further enhance retention in care for patients chronically infected with HCV.

Received July 25, 2014

Revised October 27, 2014

Accepted January 16, 2015

Published online February 14, 2015
KEY WORDS: hepatitis C; HCV screening; community-based screening; patient navigation; continuum of care.

J Gen Intern Med 30(7):950-7

DOI: $10.1007 / \mathrm{s} 11606-015-3209-6$

(C) Society of General Internal Medicine 2015

\section{INTRODUCTION}

Hepatitis $\mathrm{C}$ virus (HCV) is the most common blood-borne infection in the United States; an estimated five million Americans are chronically infected. ${ }^{1-3}$ Chronic HCV infection increases the risk for hepatic fibrosis, cirrhosis and hepatocellular carcinoma (HCC), and is the leading cause of liver transplantation. ${ }^{4}$

Early diagnosis and treatment can prevent HCV transmission and reduce HCV-related morbidity and mortality. ${ }^{5,6}$ However, 50-75\% of chronically infected individuals are unaware of their infections and will not benefit from these interventions $^{7-9}$; many are diagnosed when presenting with advanced liver disease. Advances in HCV treatments can now cure more than $90 \%$ of chronically infected individuals using interferonfree, short-term, well-tolerated regimens. ${ }^{10-14}$ New treatment regimens present important public health opportunities to reduce HCV-related morbidity and mortality.

In 2013, the Centers for Disease Control and Prevention (CDC) expanded its recommendation for HCV screening to include one-time screening for all individuals born between 1945 and 1965 and ongoing screening for other high-risk populations. ${ }^{8}$ Expanding HCV screening could help diagnose the chronically infected baby-boomers who are unaware of their infection. ${ }^{15}$ Only half of individuals who test positive for antibody to $\mathrm{HCV}$ (anti-HCV) undergo confirmatory RNA testing. ${ }^{16}$ Infrequent confirmatory testing culminates in lower than optimal diagnosis, linkage and retention in HCV care; only 12 to $18 \%$ of the total HCV-infected population has undergone disease staging with liver biopsy, and only 7 to $11 \%$ has been treated. ${ }^{17}$

Most patients who undergo HCV screening are tested in clinical settings. ${ }^{18}$ However, clinical screening may not reach 
individuals at highest risk, such as people who inject drugs, the homeless and the incarcerated. ${ }^{19}$ OraQuick's $\mathbb{C}$ HCV Rapid Antibody Test presents an opportunity to expand rapid HCV testing in community settings. Some, although few, studies have explored HCV screening and linkage-to-care programs in community and non-clinical settings. ${ }^{20-27}$

Several recent efforts describe and quantify the $\mathrm{HCV}$ care continuum. ${ }^{17,28-32}$ Most demonstrate that chronically infected individuals fail to progress through the continuum of care and have low rates of confirmatory testing, as well as barriers to accessing health insurance. ${ }^{30,33},{ }^{34}$

Many HCV infections cluster geographically ${ }^{35}$; distance from health care resources as well as socioeconomic predictors for access to care may influence HCV screening and care. ${ }^{36-40}$ Geographically focused interventions have been effective for addressing geographic disparities in human immunodeficiency virus (HIV) infection, ${ }^{41,42}$ and may offer important lessons for community-based $\mathrm{HCV}$ programs. Urban communities often have the highest rates of $\mathrm{HCV}$ infection, ${ }^{35}$ and racial and ethnic minorities have disproportionately higher HCVrelated morbidity and mortality. ${ }^{3,43}$ The city of Philadelphia, PA has a $2.9 \%$ HCV seroprevalence; select zip codes have higher prevalence. ${ }^{44}$

We developed a community-based HIV and HCV screening and linkage-to-care program in a medically underserved Philadelphia neighborhood with high rates of HIV and HCV infection. The program included a social marketing campaign to promote HIV and HCV screening, door-to-door outreach, rapid HIV and HCV screening on a mobile medical unit, immediate phlebotomy for confirmatory testing for individuals with reactive antibody tests, and patient navigation to foster linkage and retention in care for all patients with HIV and chronic HCV infection.

We present an evaluation of the community HCV testing program, including patient navigation for linkage to care. We created an HCV care continuum that highlights HCV seropositivity and important steps in the linkage and retention in care process. We describe how we overcame barriers to diagnosing, linking and retaining $\mathrm{HCV}$ patients in care.

\section{METHODS}

\section{Program Overview and Study Site}

Do One Thing is a geographically focused, neighborhoodbased HIV and HCV screening and linkage-to-care program in a medically underserved neighborhood with high rates of infection. The program provides rapid $\mathrm{HCV}$ testing in community-based settings, immediate phlebotomy for confirmatory testing for all reactive antibody tests, and comprehensive patient navigation services to engage all chronically infected patients in subspecialty $\mathrm{HCV}$ care, with intention to cure. We developed an HCV testing and linkage-to-care algorithm (Fig. 1). The Miriam Hospital and Drexel University
College of Medicine Institutional Review Boards approved this research.

\section{Testing Procedures and Data Collection}

Rapid HCV testing was performed on a mobile medical unit. Participants were recruited for testing through door-to-door and street outreach and at community events. Participants were 18 years or older and provided written informed consent.

Trained HCV test counselors explained the testing procedure to participants, and administered Oraquick $\odot$ HCV Rapid Antibody tests (OraSure Technologies Inc., Bethlehem, PA) using blood specimens obtained by fingerstick. While waiting for results, participants completed a web-based survey on iPads. Information on demographics, insurance status, risk behaviors and clinical history was collected.

All participants underwent risk reduction counseling and were educated about $\mathrm{HCV}$ prevention. $\mathrm{HCV}$ antibody test results were delivered to participants on site. Participants with non-reactive tests who reported high-risk behaviors, such as injection drug use, cocaine use or unprotected anal intercourse, were advised to test again in 3 to 6 months. Among patients with reactive tests, trained phlebotomists immediately drew blood for confirmatory testing. Blood was transported to a local hospital-based laboratory for serum separation within 6 hours of blood draw. Chronic infection was confirmed by quantitative HCV RNA real-time PCR (Ampliprep/Taqman Technology(C).

All participants with reactive rapid tests received counseling and education. Participants with reactive rapid tests met with a patient navigator and were contacted within 72 hours with confirmatory test results.

\section{Linkage to Care and Case Management}

Participants with detectable HCV RNA were notified by phone of their chronic HCV infection. Patient navigators made home visits to deliver confirmatory results for patients unreachable by phone. The process for linkage to an $\mathrm{HCV}$ specialist depended on the participant's insurance status and whether the participant had a primary care provider (PCP) upon diagnosis (Fig. 1). If a chronically infected participant had health insurance and a PCP, the patient navigator provided support in requesting a referral from the PCP to a subspecialist. This included reminding the patient to call the PCP offices, or requesting the referral in person at the PCP office on the patient's behalf. If the participant had health insurance but no PCP, the patient navigator made an appointment on the participant's behalf; those participants were then referred to subspecialists.

Uninsured participants were immediately linked to clinical social workers who guided participants through the insurance application process. When participants obtained medical coverage, patient navigators assisted them in obtaining PCPs and requesting subspecialty referrals. Patient navigators provided 


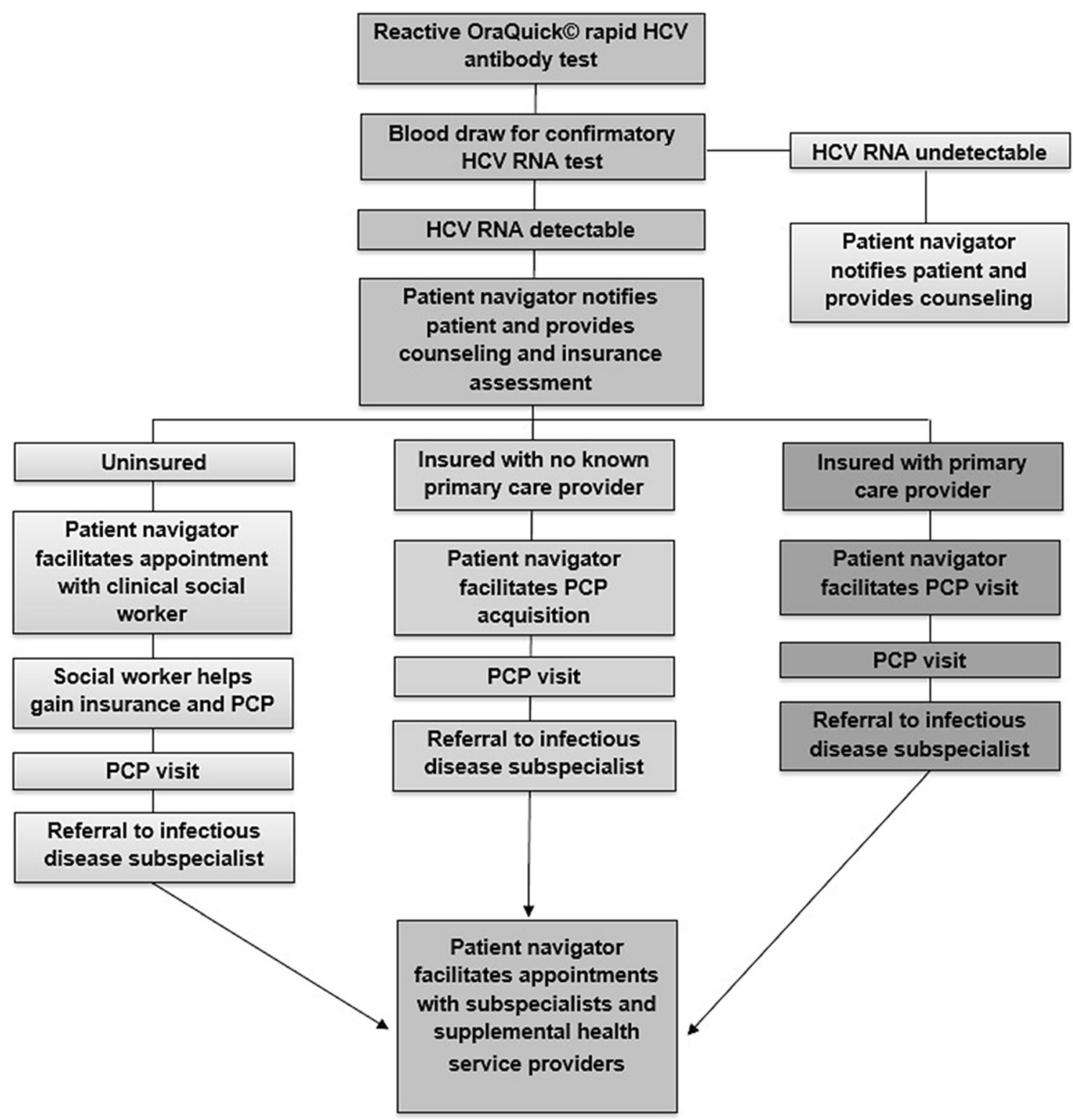

Figure 1. HCV screening and linkage-to-care protocol.

appointment reminder phone calls and text messages, made home visits, provided transit vouchers and accompanied participants to all associated medical appointments.

\section{Subspecialty Treatment}

Once insured and referred by a PCP, chronically infected participants were cared for by infectious disease (ID) specialists with $\mathrm{HCV}$ expertise. All participants received liver wellness counseling related to alcohol use, weight management and managing medications for comorbid conditions. Serologic testing for immunity to hepatitis A and B viruses was provided; vaccinations were given to non-immune participants. Abdominal ultrasound was conducted and a non-invasive assessment of liver fibrosis (FibroSure, HepaScore) was obtained. Additional lab work often included assessment of synthetic liver function (INR), complete blood count, comprehensive metabolic panel and HCV genotype. Patient navigators assisted participants in obtaining important health services that supplemented their HCV treatment plan, including mental health care and addiction services.

\section{Cascade Development}

Our HCV care continuum highlights results from our testing and linkage-to-care program. Our continuum focuses on points from diagnosis to linkage to subspecialty care and treatment; intervention endpoints highlight specific critical junctures at which patients could advance or be stymied in their HCV diagnosis and care (Fig. 2). ${ }^{31,32}$ The first step is defined as the number of individuals with reactive $\mathrm{HCV}$ antibody tests, followed by the number of individuals who 


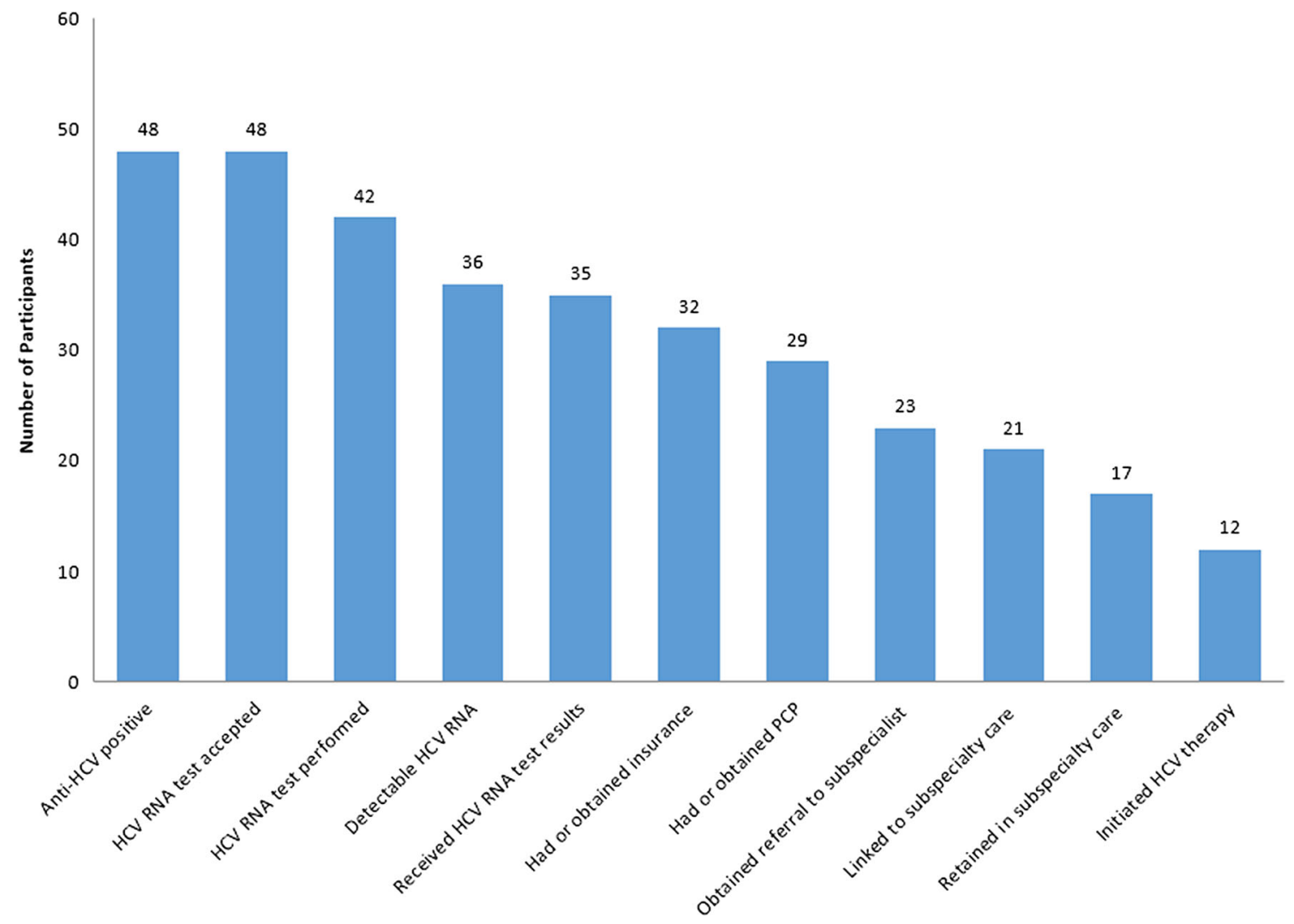

Figure 2. HCV testing and linkage-to-care cascade.

accept screening and successfully undergo phlebotomy for a confirmatory HCV RNA test. The continuum then presents individuals with detectable HCV RNA indicating chronic infection and those receiving confirmatory test results, followed by patients who have insurance at diagnosis or who obtain insurance. Because many health maintenance organizations (HMOs) require a PCP referral before seeing an HCV specialist, we included PCP referrals. The last three endpoints highlight whether patients were linked and retained in subspecialty care, and whether they initiated treatment. In Table 1, odds ratios and $95 \%$ confidence intervals based on the logit method were estimated using SAS 9.3.

\section{RESULTS}

\section{Screening Results and Reported Risk Behaviors}

We report $\mathrm{HCV}$ screening results, confirmatory testing results and linkage-to-care results for the first 16 months of our program (Fig. 2). We tested 1,301 participants for HCV on our mobile medical unit from December 2012 to February 2014 (Table 1). The majority of individuals tested were African American (91\%) and were outside the baby boomer birth cohort (71\%). Anti-HCV seroprevalence was $3.9 \%(n=52)$.

Eight percent $(n=4)$ of participants who tested positive for anti-HCV were already engaged in $\mathrm{HCV}$ care and were not offered confirmatory testing; these individuals are not included in our results (Fig. 2). We consider a patient engaged in care if they have attended at least one subspecialty appointment. All remaining anti-HCV positive participants $(n=48)$ accepted an offer for confirmatory testing and $87 \%$ $(n=42)$ had successful confirmatory tests performed. Of the remaining individuals $(n=6)$, two declined services and four await confirmatory testing appointments in clinical settings.

Among those who completed confirmatory testing $(n=42), 86 \%(n=36)$ had detectable HCV RNA indicating chronic infection; the remainder had cleared the virus (Table 1 and Fig. 2). Compared to HCV-negative participants, chronically infected participants were more likely to be male [OR 4.24 (CI 1.84, 9.76)], baby boomers [OR 10.24 (CI 4.67, 22.45)] and have an incarceration history [OR 5.35 (CI 2.55, 11.19)] (Table 1). Fifty-eight percent of these individuals $(n=21)$ were aware of their chronic infection, but not engaged in care. Confirmatory testing was provided to all participants who had a self-reported history of HCV and were not in care. Thirty-six percent $(n=13)$ of those with chronic infection were uninsured (Table 2). The remaining $64 \%(n=23)$ of those chronically infected had insurance (Table 2), but two lacked a PCP.

Approximately one quarter $(n=11)$ of participants with chronic $\mathrm{HCV}$ infection reported drinking heavily at least weekly and $58 \%(n=21)$ had an Audit-C score commensurate with an alcohol use disorder. Many participants had a history of using intravenous drugs (47\%), intranasal cocaine or crack cocaine $(72 \%)$. Eighty percent of participants had serious 
Table 1. Demographic and Behavioral Characteristics of Participants Screened for Hepatitis C (HCV)

\begin{tabular}{|c|c|c|c|}
\hline \multirow[t]{2}{*}{ Variable } & \multicolumn{2}{|l|}{ Number (Percent) } & \multirow{2}{*}{$\begin{array}{l}\text { OR }(95 \% \mathrm{CI}) \text { for chronically } \\
\text { infected compared to } \mathrm{HCV} \text { negative }\end{array}$} \\
\hline & HCV negative $(N=1,249)$ & Chronically infected participants $(N=36)$ & \\
\hline Male & $617(49.4)$ & $29(80.6)$ & $4.24(1.84,9.76)$ \\
\hline African American & $1,139(91.2)$ & 29 (80.6) & $0.40(0.17,0.93)$ \\
\hline Single & $987(79.0)$ & $27(75.0)$ & $0.80(0.37,1.71)$ \\
\hline \multicolumn{4}{|l|}{ Age } \\
\hline$<47$ & $883(71.0)$ & $8(22.2)$ & REF \\
\hline $47-67$ & $338(27.2)$ & $28(77.8)$ & $10.24(4.67,22.45)$ \\
\hline \multirow{2}{*}{\multicolumn{4}{|c|}{ Education }} \\
\hline & & & \\
\hline Less than high school & $200(16.0)$ & $12(33.3)$ & REF \\
\hline High school degree/GED & $638(51.1)$ & $18(50.0)$ & $0.53(0.25,1.10)$ \\
\hline Less than $\$ 10,000$ & $456(42.5)$ & $24(72.7)$ & REF \\
\hline$\$ 10,000-\$ 14,999$ & $194(18.1)$ & $6(18.2)$ & $0.69(0.29,1.64)$ \\
\hline$\$ 15,000-\$ 29,999$ & $208(19.4)$ & $2(6.1)$ & $0.18(0.04,0.79)$ \\
\hline$>\$ 30,000$ & $214(20.0)$ & $1(3.0)$ & $0.18(0.04,0.77)$ \\
\hline \multicolumn{4}{|c|}{ Self-identified sexual orientation } \\
\hline Heterosexual & $1,114(89.7)$ & $35(97.2)$ & REF \\
\hline Gay/Lesbian & $58(4.7)$ & $1(2.8)$ & $0.51(0.07,3.78)$ \\
\hline Bisexual & $70(5.6)$ & $0(0.0)$ & - \\
\hline \multirow{2}{*}{\multicolumn{4}{|c|}{ Heavy episodic drinking }} \\
\hline & & & \\
\hline Never & $921(74.0)$ & $17(47.2)$ & REF \\
\hline Less than monthly & $190(15.3)$ & $5(13.9)$ & $1.43(0.52,3.91)$ \\
\hline Monthly & $59(4.7)$ & $3(8.3)$ & $2.75(0.78,9.67)$ \\
\hline Weekly or more & $74(6.0)$ & $11(30.6)$ & $8.05(3.64,17.83)$ \\
\hline Audit-C alcohol use disorder & $372(29.8)$ & $21(58.3)$ & $3.30(1.68,6.47)$ \\
\hline Marijuana use ever & $729(58.4)$ & $26(72.2)$ & $1.85(0.89,3.88)$ \\
\hline Cocaine/crack use ever & $184(14.7)$ & $26(72.2)$ & $15.05(7.14,31.73)$ \\
\hline Heroin use ever & $25(2.0)$ & $12(33.3)$ & $24.5(11.02,54.38)$ \\
\hline Prescription drug use ever & $97(7.8)$ & $11(30.6)$ & $5.22(2.50,10.94)$ \\
\hline Other drug use ever & $56(4.5)$ & $9(25.0)$ & $7.10(3.19,15.81)$ \\
\hline Alcohol use at last sex & $227(18.4)$ & $17(47.2)$ & $3.96(2.03,7.75)$ \\
\hline Injection drug use & $11(0.9)$ & $17(47.2)$ & $100.21(41.42,242.43)$ \\
\hline
\end{tabular}

Values in bold are significant at $p<0.05$

comorbid psychiatric conditions, including bipolar disorder, anxiety, depression, schizophrenia, post-traumatic stress disorder, borderline personality disorder (data not shown) and alcohol use disorders (Table 1).

\section{Insurance Outcomes}

Of the 35 chronically infected individuals who received results, $66 \%(n=23)$ had insurance at the time of diagnosis. Among the remaining 12 uninsured patients, $75 \%(n=9)$ obtained health insurance after chronic infection with $\mathrm{HCV}$ was confirmed. Nine of 12 uninsured patients met with a clinical social worker and were Medicaid-eligible; eight became insured as a result of our program, and one awaits application feedback. An additional participant obtained private insurance through his spouse. The remaining two uninsured participants were lost to follow-up.

\section{PCP Referrals and Linkage to Subspecialty Care}

Only two of the 23 insured participants who received their test results did not have a primary care provider (PCP); both obtained PCPs with the support of our clinical social worker and patient navigators. Ninety percent $(n=29)$ of participants who had or gained insurance $(n=32)$ obtained a PCP.
Over three-quarters of participants with PCPs $(n=23)$ were able to obtain referrals for HCV specialty care, and $91 \%$ $(n=21)$ of these patients attended an appointment with an $\mathrm{HCV}$ specialist. More than half of previously insured participants $(n=13 ; 57 \%)$ attended an appointment with a subspecialist; $99 \%(n=9)$ saw an HCV specialist multiple times. Among the newly insured participants, nearly $90 \%(n=8)$ had HCV subspecialist appointments; over half $(n=17)$ were retained in subspecialty care. The remainder awaited subsequent subspecialty care appointments.

The remaining participants with insurance and a PCP $(n=7)$ had not obtained a HCV subspecialist referral because their PCP's information was unknown, they had been lost to follow-up, or they were not currently interested in $\mathrm{HCV}$ care.

\section{HCV Subspecialty Care Outcomes}

Most participants who were successfully linked to a subspecialist $(91 \% ; n=21)$ had multiple subspecialty appointments and were retained in care. Ninety-five percent of participants in care had undergone disease staging, including liver ultrasound and liver fibrosis panels (HepaScore or Fibrosure). Seventy-two percent were non-immune to either hepatitis A or B. The majority of non-immune participants subsequently initiated vaccine series (data not shown). 
Table 2 Health Insurance Status and Hepatitis C (HCV) Knowledge Among Chronically Infected Participants Served $(N=36)$

\begin{tabular}{ll}
\hline \hline Variable & Total (N=36) \\
\hline Insurance status* & \\
Private & $5(21.7)$ \\
Medicaid & $17(73.9)$ \\
Medicare & $6(26.1)$ \\
VA & $0(0.0)$ \\
Other & $1(4.3)$ \\
Uninsured & $13(36.1)$ \\
Primary care physician & $20(55.6)$ \\
Last primary care physician visit & \\
No PCP & $16(44.4)$ \\
In the last month & $9(25.0)$ \\
1-6 months ago & $7(19.4)$ \\
7-12 months ago & $1(2.8)$ \\
1-5 years ago & $3(8.3)$ \\
More than 5 years ago & $0(0.0)$ \\
Prior HCV test & \\
No & $7(19.4)$ \\
Yes & $25(69.4)$ \\
Don't know & $4(11.1)$ \\
Last HCV test & $7(21.9)$ \\
No prior HCV test & $1(3.1)$ \\
In the last month & $5(15.6)$ \\
1-6 months ago & $3(9.4)$ \\
7-12 months ago & $16(50.0)$ \\
More than 1 year ago & \\
Prior HCV test results & $7(19.4)$ \\
Never tested & $6(16.7)$ \\
Negative & $21(58.3)$ \\
Positive & $2(5.8)$ \\
Don't know & $34(94.4)$ \\
Have heard of HCV & \\
Self-reported HCV risk & $15(41.7)$ \\
High risk & $3(8.3)$ \\
Moderate risk & $12(33.3)$ \\
Low risk & $6(16.7)$ \\
Not at risk & \\
\hline & \\
\hline &
\end{tabular}

*Participants could report more than one type of insurance

To date, 12 patients initiated HCV therapy; many others who are treatment eligible were awaiting approval from insurance companies for payment for direct-acting antiretrovirals (DAAs).

\section{DISCUSSION}

We identified many chronic HCV infections. The overall seropositivity rate was $3.9 \%$, which is higher than Philadelphia's rate of $2.9 \%$. Many individuals who were aware of their chronic HCV infection were re-engaged in care. Immediate phlebotomy and aggressive patient navigation helped ensure linkage to subspecialty care for over half $(n=21)$ of chronically infected patients; many of the patients who had not yet seen a subspecialist were still in the process of being linked to insurance, a PCP or HCV subspecialty services.

Our findings add to the body of evidence suggesting that HCV screening in non-medical settings and subsequent patient navigation can enhance progression through the HCV care continuum. We were able to overcome many of the commonly cited barriers to $\mathrm{HCV}$ care, including access to HCV screening, confirmatory RNA testing, disease staging and treatment. ${ }^{17,25,27-30,32}$ Patient navigation services have been effective in managing other chronic conditions, such as HIV and cancer. ${ }^{45,46}$

Other HCV care continua studies present outcomes for linkage and referral to care prior to confirmatory testing in the continuum; this is because approximately half of individuals never receive confirmatory testing. ${ }^{16,17,44}$ We overcame this commonly cited barrier by conducting immediate phlebotomy and expedited HCV RNA testing. Other studies also note that not having a PCP is a barrier to engaging chronically infected individuals in $\mathrm{HCV}$ care. ${ }^{34,43}$

Notably, lack of insurance was not the greatest barrier to linking $\mathrm{HCV}$ patients to care; we were able to insure nearly all participants. Our biggest drop-off in the care continuum occurred at the subspecialty referral stage, which has not commonly been acknowledged as a barrier to care, ${ }^{21,24,31}$ perhaps because many patients never progress to requesting referrals. Most HCV providers are subspecialists, and Health Maintenance Organizations often mandate referrals from PCPs for every visit as requirements for reimbursements. Referrals often necessitate an extra PCP visit and create an opportunity for disengagement, particularly for vulnerable populations with low health literacy. However, we note that care continuum "drop-offs," presented in Fig. 2, do not always represent disengagement from care; many patients are in care but have not fully progressed through the care continuum. We note that progression through this continuum, and ultimately to treatment and cure, is an ongoing process. Repeated referral requirements and rigid preauthorization requirements associated with direct-acting antiviral therapy (DAAs) slow progression through the care continuum. For example, all patients who have been retained but are not yet initiated on antiviral therapy $(N=5)$ now await approval for medication from insurance companies. Taken together, our results suggest that dispensing with $\mathrm{HCV}$ subspecialist referral requirements and relaxing preauthorization requirements for DAAs present important opportunities to reduce barriers to HCV care and cure.

Many individuals previously aware of HCV infection had never been referred to subspecialists. Referral to a subspecialist presents an opportunity to be evaluated for curative therapy and to receive secondary prevention and risk reduction counseling a PCP may not provide. However, as treatment options for HCV continue to evolve and additional interferon-free regimens become available, it is expected that medications will be well tolerated and highly effective, with shorter durations. It is likely that $\mathrm{HCV}$ treatment may be increasingly prescribed by PCPs. Preparing PCPs to treat HCV begins with provider education and models that integrate CDC recommendations and testing algorithms into busy practices. It will also become increasingly important to disseminate information regarding new HCV treatment regimens, and to address misconceptions regarding contraindications to therapy that may contribute to barriers to 
testing and referrals to care among providers. ${ }^{47-49}$ Video conferencing to train PCPs in HCV management may be another important vehicle for scaling $\mathrm{HCV}$ treatment in underserved communities. ${ }^{50,51}$

Our patient navigators were critical for enhancing $\mathrm{HCV}$ care continuum outcomes, including explaining HCV antibody and PCR testing results to all patients, making and attending appointments, and assisting with referrals. Navigators also assisted with completing paperwork, coordinating radiology appointments and laboratory results. Our $\mathrm{HCV}$ care continuum endpoints exceed most described elsewhere. ${ }^{17,29,30}$ Notably, our confirmatory testing rates were more than double those reported elsewhere ${ }^{16,17,52}$; we attribute our success to offering on site phlebotomy and confirmatory testing. Immediate, point-of-care confirmatory testing technologies are needed to further enhance confirmatory testing and linkage to care. Similarly, we had more than double the subspecialty and disease staging rates cited elsewhere. ${ }^{17,28}$ Our results suggest that providing culturally competent, wrap-around patient navigation services was critical for successfully caring for patients with severe mental illness and a history of addiction.

\section{Limitations and Conclusion}

Our research is subject to several limitations. We did not include questions about homelessness and receptive anal sex. Perhaps somewhat surprisingly, we encountered relatively few uninsured participants. This may be because many program participants lived below the poverty line and were already enrolled in Medicaid. Many others were Medicaid-eligible. Our relative success with linking individuals to insurance may not be generalizable to other settings where a smaller fraction of individuals are Medicaid-eligible. Nevertheless, our ability to insure many high-risk individuals currently unaware of their HCV status or not engaged in HCV care highlights the importance and feasibility of community-based screening and linkage-to-care programs. We did not present data on the costs associated with this model; cost effectiveness analyses are fertile ground for future research.

Ideally, a full HCV care continuum would include data on individuals retained in care, and treated and cured individuals. Because the most effective HCV therapies were only recently approved by the U.S. Food and Drug Administration and included in many insurance formularies, many of our participants had initiated interferon-free treatment and several others were awaiting approval for treatment from insurers. Because so few participants have completed treatment, we do not present sustained virologic response data. Nevertheless, our preliminary results suggest that comprehensive patient navigation services can dramatically enhance $\mathrm{HCV}$ diagnosis and retention in care. This geographically focused outreach, screening and linkage-to-care program is indeed an effective way to diagnose, link, retain and even re-engage people in care who might not otherwise access health services.

Acknowledgements: Contributors: Amy Nunn and Stacey Trooskin led the study design, data collection and writing of this manuscript. All other authors contributed to data collection, data analysis and draft preparation. We thank Lynn Taylor, MD and Timothy Flanigan, MD for comments on previous iterations of this manuscript.

Funders: This work was supported by an HIV FOCUS grant from Gilead Sciences, as well as the National Institute on Alcohol Abuse and Alcoholism (grant KO1 AA020228), the Center for AIDS Research, National Institutes of Health (grant P3O-AI-42853, PO1AAO19072 and T32DA13911-12) and the Brown University Alcohol Research Center on HIV. The funders had no role in study design, data collection and analysis, decision to publish or preparation of the manuscript.

Prior Presentations: Preliminary findings from this study were presented at The American Association for the Study of Liver Diseases, November 2014, and The International Conference on Viral Hepatitis, March 2014

Conflicts of Interest: Amy Nunn and Stacey Trooskin receive support from Gilead Sciences, Inc. All other authors declare no conflicts of interest.

Corresponding Author: Amy S. Nunn, MS ScD; Department of Behavioral and Social Sciences Brown University School of Public Health, Bo x G-S121-8, Providence, RI 02912, USA (e-mail: amy_nunn@brown.edu).

\section{REFERENCES}

1. Armstrong GL, Wasley A, Simard EP, McQuillan GM, Kuhnert WL, Alter MJ. The prevalence of hepatitis C virus infection in the United States, 1999 through 2002. Ann Intern Med. 2006; 144(10):705-14.

2. Chak E, Talal AH, Sherman KE, Schiff ER, Saab S. Hepatitis C virus infection in USA: an estimate of true prevalence. Liver Int. 2011;31(8):1090-101. Epub 2011 Mar 15.

3. Edlin BR. Five million Americans infected with the hepatitis $\mathrm{C}$ virus: a corrected estimate [Abstract \#44]. Oral presentation at the 56th Annual Meeting of the American Association for the Study of Liver Diseases (Boston) 2005. Hepatology. 2005;42(4 Suppl 1):213A.

4. Seeff LB. Natural history of chronic hepatitis C. Hepatology. 2002;36(5 Suppl 1):S35-46.

5. Ghany MG, Strader DB, Thomas DL, Seeff LB. Diagnosis, management, and treatment of hepatitis C: an update. Hepatology. 2009;49(4):1335-74.

6. Singal AG, Volk ML, Jensen D, Di Bisceqlie AM, Schoenfeld PS. A sustained viral response is associated with reduced liver-related morbidity and mortality in patients with hepatitis C virus. Clin Gastroenterol Hepatol. 2010;8(3):280-8. Epub 2009 Nov 27.

7. Denniston MM, Klevens RM, McQuillan GM, Jiles RB. Awareness of infection, knowledge of hepatitis $\mathrm{C}$, and medical follow-up among individuals testing positive for hepatitis C: National Health and Nutrition Examination Survey 2001-2008. Hepatology. 2012;55(6):1652-61. Epub 2012 Apr 10.

8. Centers for Disease Control and Prevention. Recommendations for the identification of chronic hepatitis $\mathrm{C}$ virus infection among persons born during 1945-1965. 2012;17;61(RR04):1-18.

9. Denniston MM, Jiles RB, Drobenius J, Klevens RM, Ward JW, McQuillan GM, et al. Chronic Hepatitis C virus infection in the United States, National Health and Nutrition Examination Survey 2003 to 2010. Ann Intern Med. 2014;160(5):293-300.

10. Chung RT. A watershed moment in the treatment of hepatitis C. N Engl J Med. 2012;366(3):273-5.

11. Osinusi A, Meissner EG, Lee YJ, Bon D, Heytens L, Nelson A, et al. Sofosbuvir and ribavirin for hepatitis $\mathrm{C}$ genotype 1 in patients with unfavorable treatment characteristics: a randomized clinical trial. JAMA. 2013;310(8):804-11. 
12. Lawitz E, Mangia A, Wyles D, Rodriguez-Torres M, Hassanein T, Gordon SC, et al. Sofosbuvir for previously untreated chronic hepatitis $\mathrm{C}$ infection. N Engl J Med. 2013;368(20):1878-87.

13. Schmidt WN, Nelson DR, Pawlotsky JM, Sherman KE, Thomas DL, Chung RT. Direct-Acting Antiviral Agents and the Path to Interferon Independence. Clin Gastroenterol Hepatol. 2014;12(5):728-737. Epub 2013 Jul 18.

14. Chung RT, Baumert TF. Curing chronic hepatitis C-the arc of a medical triumph. N Engl J Med. 2014;370(17):1576-8.

15. Rein DB, Smith BD, Wittenborn JS, Lesesne SB, Wagner LD, Roblin Dw, et al. The cost-effectiveness of birth-cohort screening for hepatitis C antibody in U.S. primary care settings. Ann Intern Med. 2012;156(4):263-70.

16. Centers for Disease Control and Prevention. Vital signs: evaluation of hepatitis C virus infection testing and reporting - eight U.S. sites, 20052011. 2013;10;62(18):357-61.

17. Holmberg SD, Spradling PR, Moorman AC, Denniston MM. Hepatitis C in the United States. N Engl J Med. 2013;368(20):1859-61.

18. Centers for Disease Control and Prevention. Locations and reasons for initial testing for hepatitis C infection - chronic hepatitis cohort study, United States, 2006-2010. 2013;62(32):645-8.

19. Beckwith CG, Kurth A, Bazerman L, Solomon L, Patry E, Rich JD, Kuo I. HCV Testing in correctional facilities: a routine testing recommendation is urgently needed. Am J Public Health. Forthcoming 2014.

20. Norton BL, Voils CI, Timberlake SH, Hecker EJ, Goswami ND, Huffman KM, et al. Community-based HCV screening: knowledge and attitudes in a high risk urban population. BMC Infect Dis. 2014;14:74.

21. Wong Vw, Wong GL, Chim AM, Cheng TF, Cheung SW, Lai CM, et al. Targeted hepatitis C screening among ex-injection drug users in the community. J Gastroenterol Hepatol. 2014;29(1):116-20.

22. Martin NK, Hickman MN, Miners A, Hutchinson SJ, Taylor A, Vickerman P. Cost-effectiveness of HCV case-finding for people who inject drugs via dried blood spot testing in specialist addiction services and prisons. BMJ Open. 2013;3(8).

23. Fusfeld L, Aggarwal J, Dougher C, Vera-Lonch M, Bubb S, Donepudi M, et al. Assessment of motivating factors associated with the initiation and completion of treatment for chronic hepatitis C virus (HCV) infection. BMC Infect Dis. 2013;13:234.

24. Swan D, Long J, Carr O, Flanagan J, Irish H, Keating S, et al. Barriers to and facilitators of hepatitis $\mathrm{C}$ testing, management, and treatment among current and former injecting drug users: a qualitative exploration. AIDS Patient Care STDS. 2010;24(12):753-62.

25. Masson CL, Delucchi KL, McKnight C, Hettema J, Khalili M, Min A, et al. A randomized trial of a hepatitis care coordination model in methadone maintenance treatment. Am J Public Health. 2013;103(10):e81-8.

26. Perumalswami PV, Factor SH, Kapelusznik L, Friedman SL, Pan CQ, Chang C, et al. Hepatitis Outreach Network: a practical strategy for hepatitis screening with linkage to care in foreign-born communities. J Hepatol. 2013;58(5):890-7.

27. Grebely J, Oser M, Taylor LE, Dore GJ. Breaking down the barriers to hepatitis $\mathrm{C}$ virus (HCV) treatment among individuals with $\mathrm{HCV} / \mathrm{HIV}$ coinfection: action required at the system, provider, and patient levels. J Infect Dis. 2013;207(Suppl 1):S19-25.

28. Moorman AC, Gordon SC, Rupp LB, Spradling PR, Tashale EH, Lu M, et al. Baseline characteristics and mortality among people in care for chronic viral hepatitis: the chronic hepatitis cohort study. Clin Infect Dis. 2013;56(1):40-50.

29. Cachay ER, Hill L, Wyles DL, Torriani FJ, Ballard C, Colwell B, et al. The hepatitis $\mathrm{C}$ cascade of care among HIV infected patients following diagnosis of HCV infection [Abstract 672]. Top Antivir Med. 2014;22(e-1):335.

30. Yehia BR, Schranz AJ, Umscheid CA, Lo Re III V. The treatment cascade for chronic hepatitis $\mathrm{C}$ virus infection in the United States: A systemic review and meta-analysis. PLoS ONE. 2014;9(7):e101554-e101554.

31. Afdhal NH, Zeuzem S, Schooley RT, Thomas DL, Ward JW, Litwin AH, et al. The new paradigm of hepatitis $\mathrm{C}$ therapy: integration of oral therapies into best practices. J Viral Hepat. 2013;20(11):745-60.

32. Mehta SH, Genberg BL, Astemborski J, et al. Limited uptake of hepatitis $\mathrm{C}$ treatment among injection drug users. J Community Health. 2008;33(3):126-33.
33. Ditah IC, Ngwa T, Ditah CM, Ewelukwa O, Kamath PS. Bridging the gap between HCV screening and access to necessary care: National Health and Nutrition Examination Survey HCV follow-up, 2001-2010 [Su 1027]. Gastroenterology. 2014;146(5 Suppl 1):S-966.

34. Linas BP, Barter DM, Leff JA, Assoumou SA, Salomon JA, Weinstein MC, et al. The hepatitis $\mathrm{C}$ cascade of care: identifying priorities to improve clinical outcomes. PLOS One. 2014;9(5):e97317.

35. Trooskin SB, Hadler J, St Louis T, Navarro VJ. Geospatial analysis of hepatitis $\mathrm{C}$ in Connecticut: a novel application of a public health tool. Public Health. 2005;119(11): 1042-7.

36. Astell-Burt T, Flowerdew R, Boyle P, Dillon J. Is travel-time to a specialist center a risk factor for non-referral, non-attendance and loss to follow-up among patients with hepatitis C (HCV) infection? Soc Sci Med. 2012;75(1):240-7.

37. Astell-Burt T, Flowerdew R, Boyle PJ, Dillon JF. Does geographic access to primary healthcare influence the detection of hepatitis C? Soc Sci Med. 2011;72(9): 1472-81.

38. Monnet E, Ramée C, Minello A, Jooste V, Carel D, Di Martino v. Socioeconomic context, distance to primary care and detection of hepatitis C: a French population-based study. Soc Sci Med. 2008;66(5):1046-56.

39. Stepanova M, Kanwal F, El-Serag HB, Younossi ZM. Insurance status and treatment candidacy of hepatitis C patients: analysis of populationbased data from the United States. Hepatology. 2011;53(3):737-45.

40. Searson G, Engelson SE, Carriero D, Kotler DP. Treatment of chronic hepatitis $\mathrm{C}$ virus infection in the United States: some remaining obstacles. Liver Int. 2014;34(5):668-71.

41. Nunn A, Yolken A, Cutler B, Trooskin S, Wilson P, Little S, et al. Geography Should Not Be Destiny: Focusing HIV/AIDS Implementation Research and Programs on Microepidemics in US Neighborhoods. Am J Public Health. 2014;104(5):775-80.

42. Meyers JE, Braunstein SL, Shepard CW, Cutler BH, Mantsios AR, Sweeney MM, et al. Assessing the impact of a community-wide HIV testing scale-up initiative in a major urban epidemic. J Acquir Immune Defic Syndr. 2012;61(1):23-31.

43. Tohme RA, Xing J, Liao Y, Holmberg SD. Hepatitis C testing, infection, and linkage to care among racial and ethnic minorities in the United States, 2009-2010. Am J Public Health. 2013;103(1):112-9.

44. Viner K, Kuncio D, Newbern EC, Johnson CC. The continuum of hepatitis c testing and care. Hepatology. 2014. doi:10.1002/hep.27584.

45. Wells KJ, Battaglia TA, Dudley DJ, Garcia R, Greene A, Calhoun E, et al. Patient Navigation Research Program. Patient navigation: state of the art or is it science? Cancer. 2008;113(8):1999-2010.

46. Vargas RB, Cunningham WE. Evolving trends in medical carecoordination for patients with HIV and AIDS. Curr HIV/AIDS Rep. 2006;3(4):149-53.

47. Ferrante JM, Winston DG, Chen P-H, de la Torre AN. Family physicians knowledge and screening of chronic hepatitis and liver cancer. Fam Med. 2008;40(5):345-51.

48. Shehab TM, Sonnad SS, Lok AS. Management of hepatitis C patients by primary care physicians in the USA: results of a national survey. J Viral Hepat. 2001;8:377-83.

49. Trooskin SB, Navarro VJ, Winn RJ, Axelrod DJ, McNeal AS, Velez M, et al. Hepatitis C risk assessment, testing and referral for treatment in urban primary care: Role of race and ethnicity. World $\mathrm{J}$ Gastroenterol. 2007;13(7):1074-10.

50. Arora S, Thornton K, Murata G, Deming P, Kalishman S, Dion D, et al. Outcomes of treatment for hepatitis C virus infection by primary care providers. N Engl J Med. 2011;364(23):2199-207.

51. Mitruka K, Thornton K, Cusick S, Orme C, Moore A, Manch RA, et al. Division of Viral Hepatitis, National Center for HIV/AIDS, Viral Hepatitis, STD and TB Prevention, CDC. Expanding primary care capacity to treat hepatitis $\mathrm{C}$ virus infection through an evidencebased care model - Arizona and Utah, 2012-2014. MMWR Morb Mortal Wkly Rep. 2014;63(18):393-8.

52. Stockman LA, Guilfoyle SM, Benoit AL, Vergeront JM, Davis JP. Rapid hepatitis C testing among persons at increased risk for infection Wisconsin, 2012-2013. MMWR Morb Motal Wkly Rep. 2014;63(14):309311. 